\title{
ARTICLES
}

\section{TO EVALUATE THE EFFECTIVENESS OF STRUCTURED TEACHING PROGRAMME ON KNOWLEDGE REGARDING VARICOSE VEINS AND ITS PREVENTION AMONG OT AND ICU STAFF NURSES}

Mr. Abhimanyu Sharma* | Dr. Rajendra Prasad Sharma**

*PhD Scholar, \& Associate Professor, Sharda College of Nursing, Sodawas (Alwar) Rajasthan, India

**Associate Professor, Mahatma Gandhi Nursing College Jaipur, Rajasthan, India

DOI: http://doi.org/10.47211/idcij.2021.v08i03.005

\begin{abstract}
Many factors predispose human beings to a disease of the lower extremities, and this condition affects approximately eighty million Americans. Its manifestationsmay appear to be little more than a cosmetic nuisance, yet it may be an indication of a more serious underlying problem undetected byvisual inspection. Venous disease is also capable of producing a plethora of uncomfortable symptoms, and left untreated, may progress to cutaneous pigmentation, dermatitis, ulceration, haemorrhage, or superficial thrombophlebitis. Although uncomplicated cases of the disease are more common, venous disease should not be taken lightly. Steps to retard disease expression and prog ression should be implemented whenever possible. As blood rushes through our legs the veins send it back to the heart. In case of prolonged standing, due to force of gravity the veins lose their ability to push the blood upwards, causing the blood to settle down in certain areas of the veins. Varicose veins are tortuous, distended and bulging veins (varicosities) beneath the skin of the legs. They are most often swollen and gnarled veins that most frequentlyoccur in the legs, ankles and feet.

Even though the exact cause of varicose veins is unknown, there are some risk factors which contribute to development of this problem. Some of the risk factors are, low physical activity, smoking, family heredity of va ricose veins, congenital valve orvein wall defects, valve damage from trauma, obstruction, deep vein thrombosis (DVT) or inflammation, chronic venous distention associated with occupations requiring prolonged standing, obesity or pregnancy, systemic conditions that interfere with venous return and loss of vein wall elasticity with ageing.
\end{abstract}

Key Words: Varicosities, Psychological Hazard, Preventable, Vascular Disease.

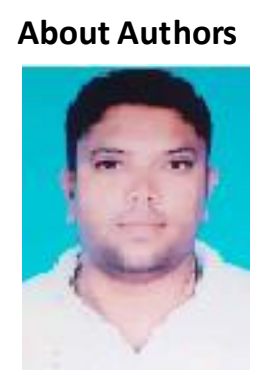

Author Mr. Abhimanyu Sharma is a PhD scholar and an Associate Professor at Sharda College of Nursing, So dawas (Alwar), Rajasthan, India.

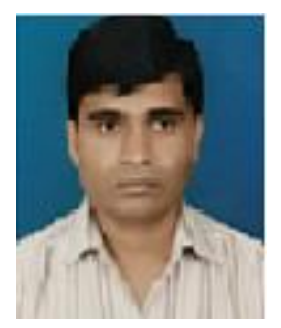

Author Dr. Rajendra Prasad Sharma is currently working as Associate Professor at Mahatma Gandhi Nursing College Jaipur, Rajasthan, India. He is also a Research Guide for PG and Ph.D. Scholars. He has presented papers at various seminars and conferences 


\section{ARTICLES}

\section{INTRODUCTION}

Nurses are an integral component of healthcare delivery system. In discharging their duties, nurses encounter a variety of occupational health problems, which may be categorised into biological hazards, physical hazards and psychological hazards. Nurses constitute the largest category of health care workers in most countries, and have a critical role in the health care delivery system. Nurses generally serve as the primary interface with patients. It would be fair to state that the health care delivery system would cease to function in absence of nurse s.

Varicose vein is one of the chief preventable diseases which are associated with veins. It is a serious dise ase, which poses threat of life of a patient when effective and efficient measures are not taken.

Varicose veins are common in the superficial veins of the legs which are subject to high pressure when standing. Accumulation of more and more venous blood in the superficial venous system makes the superficial ve ins dilated and tortuous. This condition of dilated and tortuous veins in the leg due to damaged valve betwe en the de ep and superficial venous system is called varicose vein.

Varicose vein is most common in women and in people whose occupations require prolonged standing, te achers, traffic police, bus conductors, machine workers, construction workers and pregnant women. The deep and superficial veins get damaged because of prolonged standing. Ones the vein is damaged there is a reversal of blood flow from deep to superficial vein.

As the heart beats, it pumps blood through a system of blood vessels called the circulatory system. The ve ssels are elastic tubes that carry blood to every part of the body. Arteries carry blood away from the heart while veins return it. Vascular disease includes any condition that affects the circulatory system.

Varicose vein is the most common type of vascular disease. Varicose veins are dilated, tortuous, elongated and superficial veins that are usuallyseen in the legs. Superficial veins (saphenous vein) of the legs are most commonly affected.

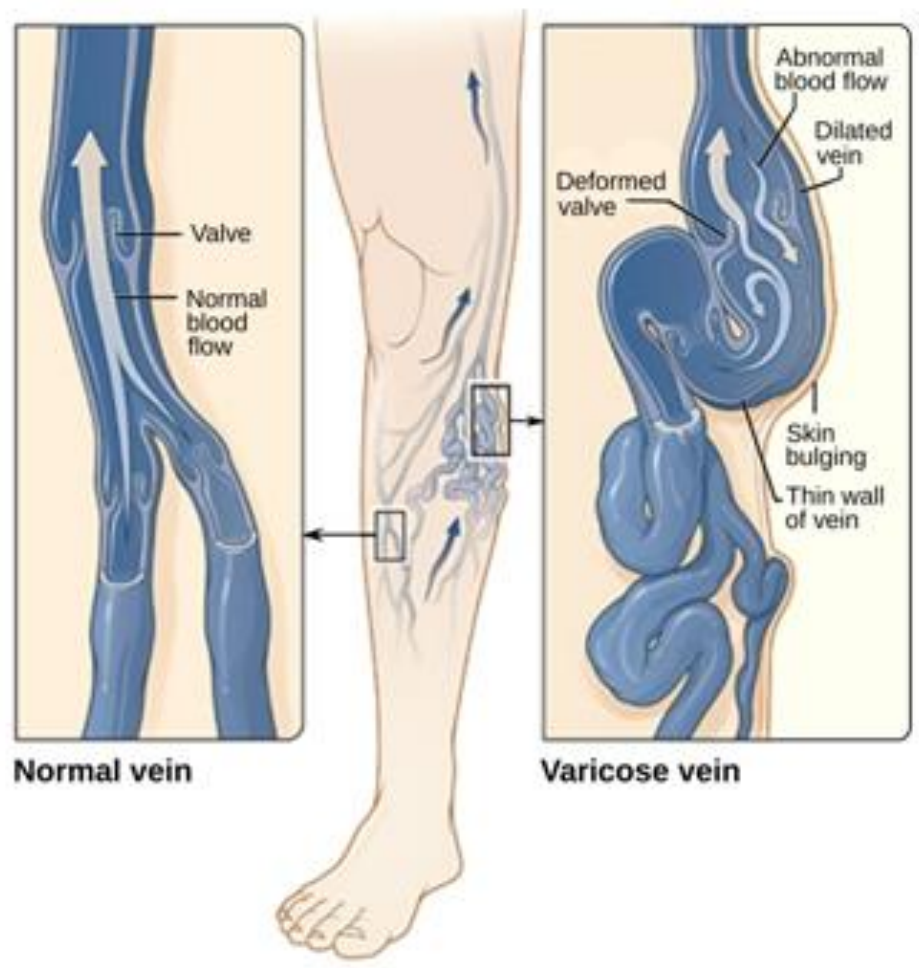

Chronic venous disease is the most common vascular condition to affect the lower limbs. Varicose veins being one among the chronic venous dise ases are common among people whose occupation requires long standing. 


\section{ARTICLES}

\section{NEED FOR THE STUDY}

Abnormally dilated, elongated and torturous alteration in the veins and their tributaries is called as varicose veins. Varicose veins are twisted, enlarged veins, often dark blue in colour, closer to the surface of the skin main ly se en in the lower limbs. Professions involving standing or sitting for prolonged periods of time have an increased risk of developing varicose veins i.e., store clerks, waitresses, hair dressers, flight attendants, teachers and nurses.

One of the major goals in the field of health promotion and disease prevention is to identify riskfactors for disease so that information about these risk factors can then be shared with people and the hope is that pe ople will use this information to change their behaviour to lower their disease risk. There are three major problems with this model. The first problem is that it is very difficult to identify disease risk factors. The second problem is that even when we do identify disease risk factors, we have a very difficult time in getting people to change their behaviour. Many research studies have shown that even when people know about riskfactors for the disease, this ofte $n$ does not result in the ir change in behaviour to lower the risk. Most behaviour changes occur, in fact, in response to a variety of environmental and community forces that constrain and modify behaviour.

\section{OBJECTIVES}

1. Assess the Pre-test knowledge score regarding varicose veins and its prevention among OT and ICU nurses.

2. Assess the Post-test knowledge score regarding varicose veins and its prevention among OT and ICU nurses.

3. To evaluate the effectiveness of structured teaching programme on knowledge regarding varicose ve ins and its prevention among OT and ICU nurses.

4. Find out the association between Post-test knowledge scores and selected demographic variables.

\section{ASSUMPTIONS}

The study assumes that -

1. OT and ICU nurses have knowledge regarding varicose veins and their prevention.

2. Structured Teaching Programme will enhance the level of knowledge on varicose ve ins and the ir prevention among OT and ICU nurses.

3. Improvement in knowledge will enable the OT and ICU nursesto take measures in preventing the occurrence of varicose veins.

\section{HYPOTHESIS}

$\mathbf{H}_{1}$ - The mean Post-test knowledge score will be significantly higher than the mean Pre-test knowledge score regarding varicose veins and their prevention.

$\mathbf{H}_{2}$ - There will be significant association of Post-test knowledge score regarding varicose veins and their prevention with selected demographic variables.

\section{RESEARCH METHODOLOGY}

Research Methodology is a way of systematically solving the research problem. It is a science of studying how research is done scientifically. 


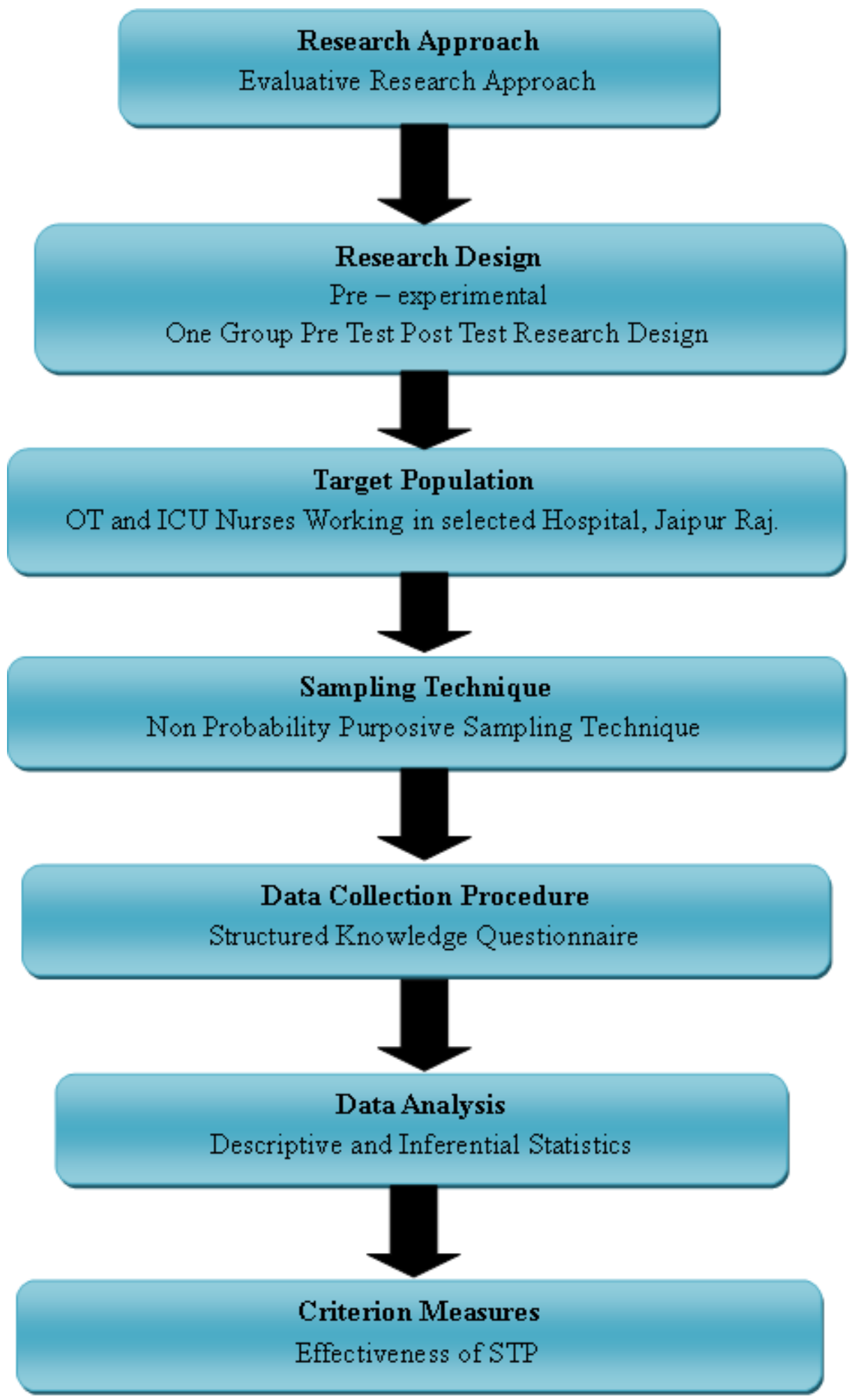

Fig. 1: Schematic representation of Research Methodology 


\section{ARTICLES}

\section{DATA ANALYSIS AND INTERPRETATION}

Table - 1: Distribution of OT and ICU nurses according to Demographic information

$\mathbf{N}=60$

\begin{tabular}{|l|l|c|c|}
\hline \multicolumn{2}{|c|}{ Demographic Variable } & Frequency & Percentage (\%) \\
\hline Age (In years) & $20-30$ & 20 & 33.33 \\
\cline { 2 - 4 } & $30-40$ & 15 & 25.00 \\
\cline { 2 - 4 } & $40-50$ & 15 & 25.00 \\
\cline { 2 - 4 } & $>50$ & 10 & 16.66 \\
\hline Gender & Female & 45 & 75.00 \\
\cline { 2 - 4 } & Male & 15 & 25.00 \\
\hline Professional qualification & G.N.M. & 25 & 41.66 \\
\cline { 2 - 4 } & Basic B. Sc. Nursing & 10 & 16.66 \\
\cline { 2 - 4 } & Post Basic B.Sc. Nursing & 20 & 33.33 \\
\cline { 2 - 4 } & M. Sc. Nursing & 05 & 08.33 \\
\hline Working experience & $0-5$ Years & 20 & 33.33 \\
\cline { 2 - 4 } & $5-10$ Years & 20 & 33.33 \\
\cline { 2 - 4 } & $10-15$ Years & 15 & 25.00 \\
\cline { 2 - 4 } & More than 15 Years & 05 & 08.33 \\
\hline Previous knowledge & Yes & 20 & 33.33 \\
\cline { 2 - 4 } & No & 40 & 66.66 \\
\hline
\end{tabular}

Table .2: It shows Mean, Mean percentage and Standard deviation of area-wise Pre-test knowledge scores of OT and ICU nurses

\begin{tabular}{|c|c|c|c|c|c|}
\hline SI. No. & Area & Maximum Score & Mean & Mean (\%) & S.D. \\
\hline 1. & $\begin{array}{l}\text { Questions related to varicose } \\
\text { veins - causes and symptoms }\end{array}$ & 11 & 5.267 & 52.67 & 1.200 \\
\hline 2. & Question related to manage ment & 10 & 5.016 & 50.16 & 1.072 \\
\hline 3. & $\begin{array}{l}\text { Questions related to prevention } \\
\text { and control }\end{array}$ & 09 & 5.220 & 52.20 & 1.066 \\
\hline 4. & Overall maximum score & 30 & 15.500 & 51.66 & 1.565 \\
\hline
\end{tabular}

Table .2 depicted area wise mean, mean percentage, standard deviation and overall score in Pre- te st knowledge scores of OT and ICU nurses comprising three sections on varicose veins. 


\section{ARTICLES}

Table .3 It shows Mean, Mean percentage and Standard deviation of area-wise Post-test knowledge scores of OT and ICU nurses

$N=60$

\begin{tabular}{|c|l|c|c|c|c|}
\hline Sl. No. & \multicolumn{1}{|c|}{ Area } & Maximum Score & Mean & Mean (\%) & S.D. \\
\hline 1. & $\begin{array}{l}\text { Questions related to varicose } \\
\text { veins - causes and symptoms }\end{array}$ & 11 & 8.7 & 87.00 & 0.971 \\
\hline 2. & Question related to management & 10 & 9.233 & 92.33 & 0.782 \\
\hline 3. & $\begin{array}{l}\text { Questions related to prevention } \\
\text { and control }\end{array}$ & 09 & 8.5667 & 85.66 & 0.644 \\
\hline 4. & Overall maximum score & 30 & 26.5 & 88.33 & 0.866 \\
\hline
\end{tabular}

Table no. 2.2 depicted area wise mean, mean percentage, standard deviation and overall score in Post-test knowledge scores of OT and ICU nurses comprising three sections on varicose veins.

Table .4: Percentage distributions of overall knowledge level and knowledge in specific areasrelated to varicose veins and its prevention in Pre-test \& Post-test

$N=60$

\begin{tabular}{|c|l|c|c|c|c|c|}
\hline \multirow{2}{*}{ SI. No. } & \multirow{2}{*}{ Level of Knowledge } & \multirow{2}{*}{$\%$ of score } & \multicolumn{2}{|c|}{ Pre-test } & \multicolumn{2}{c|}{ Post-test } \\
\cline { 4 - 7 } & & & Frequency & Percentages (\%) & Frequency & Percentages \% \\
\hline 1. & Poor & $<50 \%$ & 31 & 51.66 & 00 & 00 \\
\hline 2. & Average & $50 \%-75 \%$ & 29 & 48.34 & 00 & 00 \\
\hline 3. & Good & $>75 \%$ & 00 & 00 & 60 & 100 \\
\hline
\end{tabular}

The level of knowledge was classified in three aspects which include poor $(<50 \%)$, average $(50-75 \%)$, goo $d(>75 \%)$. The data of table No. 2.3 show that in Pre-test, majority of the subjects $51.66 \%$ (31) had poor knowledge and $48.34 \%$ (29) subjects had average knowledge about the topic, and $0 \%$ (none) had good knowledge. The above presented data reveal that in the assessment of Post-test knowledge, majority $100 \%$ (60) of subjects had good knowledge.

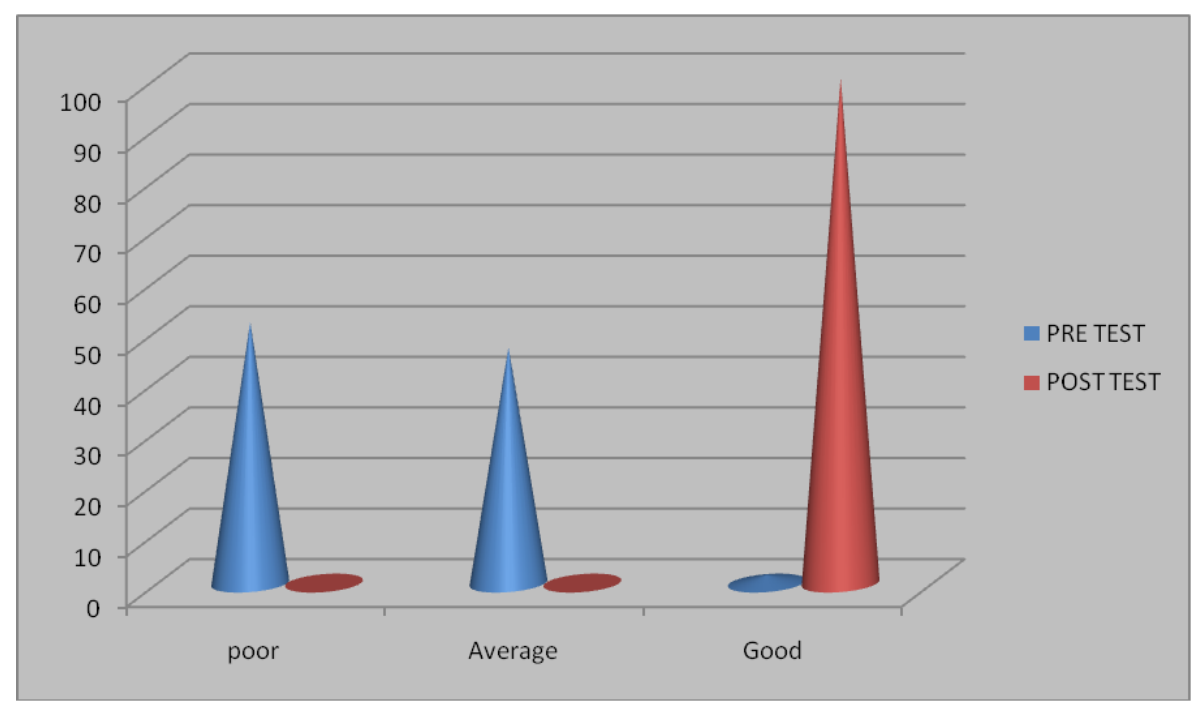

Fig. 2: Percentage distributions of overall knowledge level related to varicose veins and its prevention in Pre-test \& Post-test 


\section{ARTICLES}

In Pre-test, majority of the subjects, $51.66 \%$ (31) had poor knowledge and $46.67 \%$ (28) subjects had average knowledge about the topic, and $1.67 \% \%(01)$ had good knowledge. The above presente $d$ data reveal that in the assessment of Post-test knowledge, majority $100 \%$ (60) of subjects had good knowledge.

Table .5: Mean, Median and Standard deviation of Pre-test and Post-test knowledge scores of staff nurses on the structured knowledge questionnaire

\begin{tabular}{|l|c|c|c|c|c|}
\hline Knowledge test & Mean & Median & SD & Df & 'z' test \\
\hline Pre-test & 15.5 & 15 & 1.565 & \multirow{2}{*}{59} & \multirow{2}{*}{65.469} \\
\cline { 1 - 4 } Post-test & 26.5 & 27 & 0.866 & & \\
\hline
\end{tabular}

Maximum score: 30 , Minimum score: 0

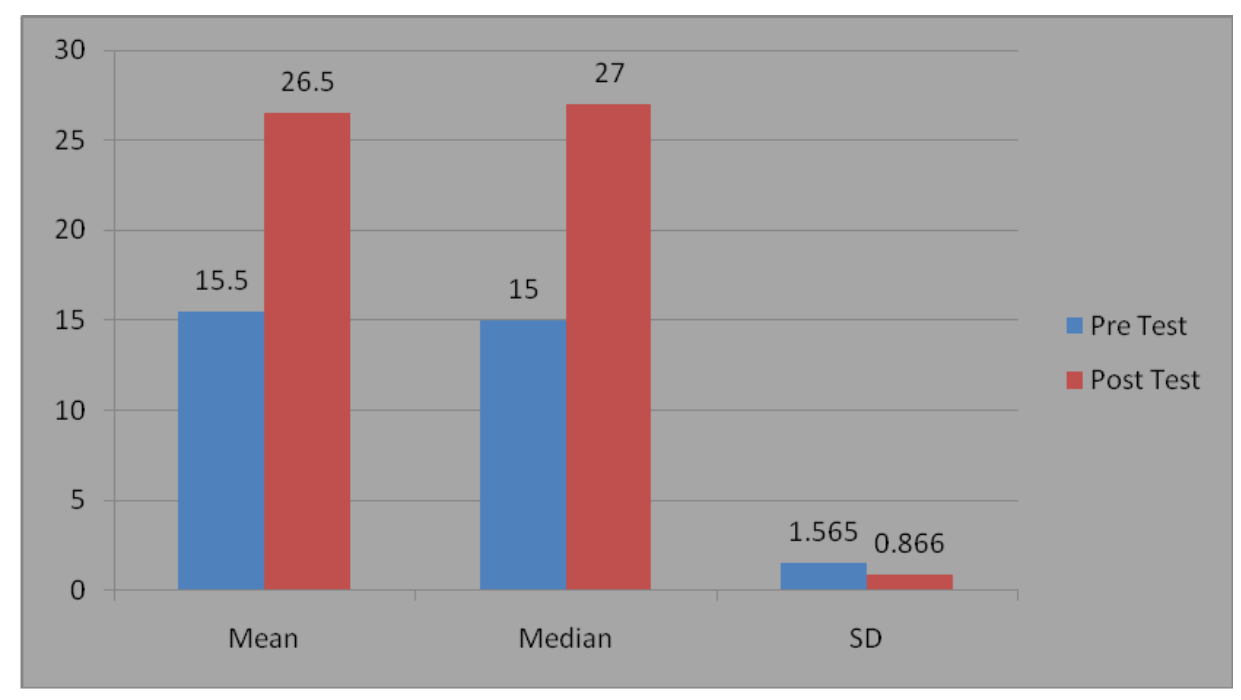

Fig. 3: Diagram showing the Mean, Median and Standard deviation of Pre-test and Post-test knowledge scores of OT and ICU nurses.

The bar diagram in Figure 3 shows the Mean Pre-test and Mean Post-test knowledge scores of staff nurses. It is evident from the bar graph that the mean knowledge score of Post-test (26.5) was higher than the mean knowledge score of Pre-test (15.5). The Median of the Post-test (27) is higher than the Median of the Pre-test knowledge sco re (15). The findings also revealed that the Post-test knowledge scores are more homogenous (SD 0.866) than the Pretest knowledge scores (SD 1.565).

Table .6: Association of knowledge scores of subjects with their demographic variables

\begin{tabular}{|l|c|c|c|c|}
\hline Demographic Variable & df & Tabulated Value & Calculated Value & Finding \\
\hline Age & 6 & 12.59 & 14.000 & Significant \\
\hline Gender & 2 & 5.99 & 1.128 & Not Significant \\
\hline Professional Qualification & 6 & 12.59 & 13.161 & Significant \\
\hline Working Experience & 6 & 12.59 & 13.857 & Significant \\
\hline Previous knowledge & 2 & 5.99 & 9.937 & Significant \\
\hline
\end{tabular}




\section{ARTICLES}

\section{CONCLUSION}

The following conclusions were drawn on the basis of findings of the study:-

- The mean score of staff nurses before administration of STP was 15.5.

- The median score of staff nurses before administration of STP was 15.

- The standard deviation score of staff nurses before administration of STP was 1.565

- The mean score of staff nurses after administration of STP was 26.5.

- The median score of staff nurses after administration of STP was 27.

- The standard deviation score of staff nurses after administration of STP was 0.866

- $\quad$ The $Z$ test value at $59 \mathrm{df}$ was 65.469 .

- It was concluded that the tabulated value is less than the calculated value.

- It was concluded that the structured teaching programme regarding varicose veins and the ir prevention was effective to enhance the knowledge of staff nurses.

\section{REFERENCES}

1. Brunner and Siddharth's. Text book of Medical and Surgical nursing $10^{\text {th }}$ edition. Wolters kluwer company Philadelphia; 2004.

2. Afolabi, M. The review of related literature in research, International Journal of Information and Library Research, 4(1), 59-66.

3. Malcolm R. Colmer. Moroney's surgery for Nurses. $16^{\text {th }}$ Edition. Churchill living stone $; 2010$.

4. http://www.medicinenet.com/vascular_disease/article.htm.

5. http://www.faqs.org/health/topics/38/Varicose-veins.html.

6. Sadick NS, Predisposing factors of varicose veins, J Dermatol Surg Oncol: (serial online) 2012, vol 18, p.883-6

7. Johnson MT. Treatment and Prevention of varicose veins. JVasclr Nur [abstract] 2011; 15(3):97-103.

8. Bailey H, Love NRJ. Short Practice of Surgery. $23^{\text {rd }}$ ed. London: Hodder Arnold, 2015: 235-45.

9. Freischlag JA, Heller JA, Venous disease. In: Townsend CM, Beauchamp RD, Evers BM, Mattox KL, eds. Sabiston Textbook of Surgery. $19^{\text {th }}$ ed. Philadelphia. Pa: Saunders Elsevier: 2012, Chapter 65.

10. Benjamin W Van Voorhees. Mayo Foundation for Medical Education and Research 2012.www. Medline.com.

11. S Leonard Syme, The prevention of disease and promotion of Health: the need for a new approach, Eu ropean Journal of Public Health, Vol 17, Number 4, p. 329-330.

12. Joshi H B, Newns N, Stainthrope A, MacDonagh RP, Keeley FX, Timoney AG. The development of patient information booklet on Ureteric stents. BJU Int 2015 September: 88(4):329-334. http:// www. Ncbi. $\mathrm{n} / \mathrm{m}$.govt/sites/entrez. 